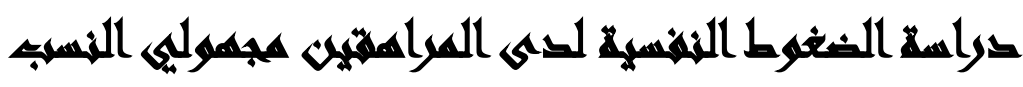

\section{بالمؤسمايت الإيوائية}

[Ir]

جمال أحمد شفيق(')- رشاد أحمد عبد اللطيف(؟) - أحمد فخرى هانى(r)

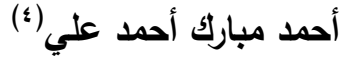

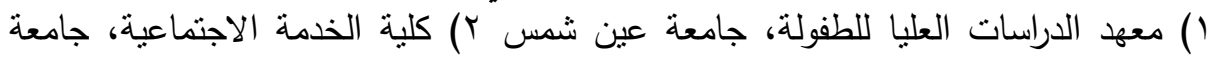

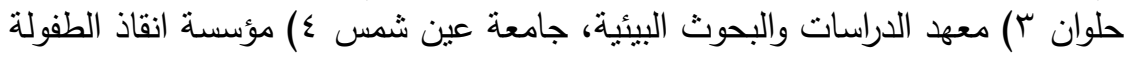

\section{المستلنه}

يهدف البحث الي التعرف على طبيعة مصادر الضغوط النفسية، وإيجاد العلاقة بين كل الفئل

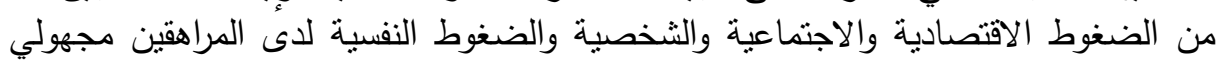

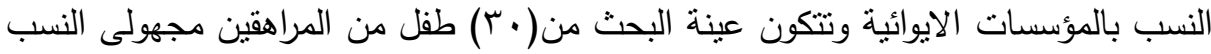

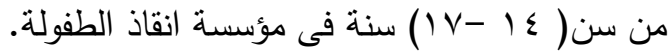

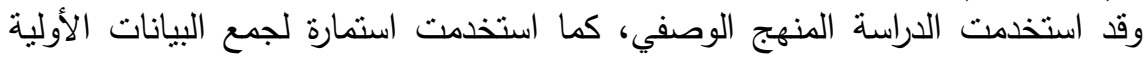

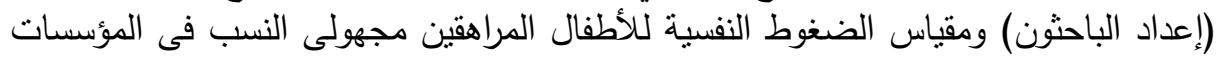
الايوائية (إعداد الباحثون) واستنيان مفتوح (إعداد الباحثثن).

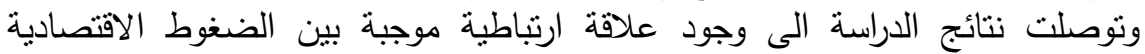

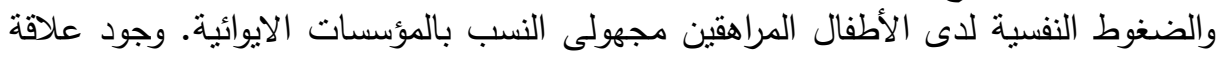

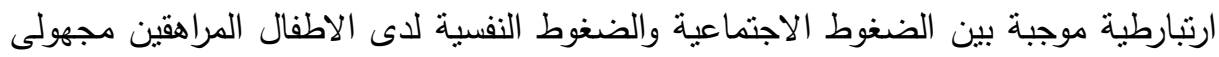

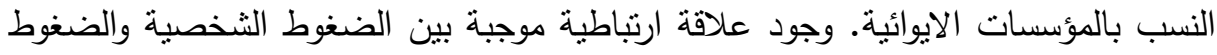

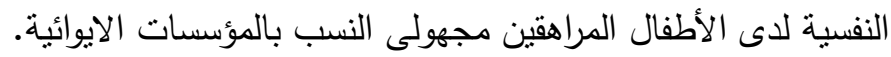

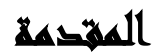

تعتبر ظاهرة الضعوط النفسية من الظواهر الانسانية المعقدة التى تتجلى فى مضامين

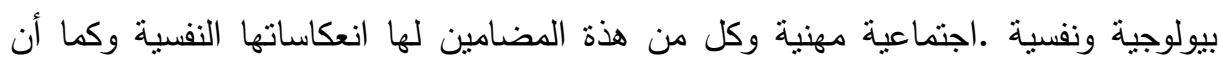
نواتج هذة الضغوظ نظهر فى مخرجات فسيولوجية ونفسية سئية وفي الحقيقة نرى ان الوقائع الاجنماعية والاقتصادية والسياسية والمهنية وغيرها تكتسب معناها كما يدركها الفرد.

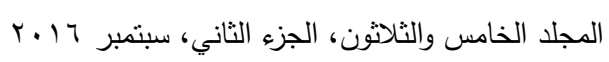


وترجع المشكلات النفسية والضغوط النفسية فى المقام الأول الى سوء نوافق الفرد مع نفسه ومع البيئة بسبب فثله فى تحقيق اهدافه وأرضاء حاجاته النفسية والجسمية والاجتماعية

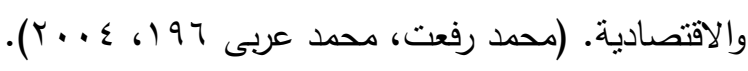
ويعرف Walker (2001) ، الضغوط النفسية بأنها حالة إنفعالية تتشأ عندما يواجه

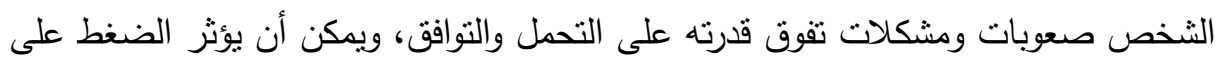
صحة الإنسان وسلادته، لأنه يخلق داخل الفرد ردود فعل نفسية قصبيرة وطويلة الأجل.

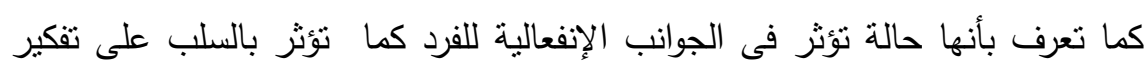

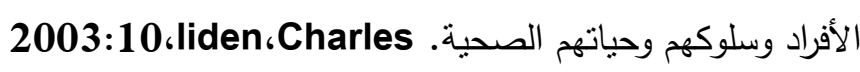
ويعرف E، Adams

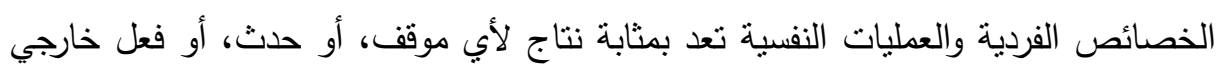
يلقى بأعباء فسيولوجية أو نفسية على الفرد.

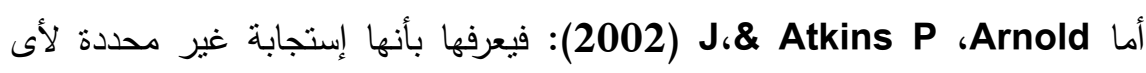
نشاط يتطلب التوافق، وتظهر تلك الضغوط أو التوتر من خلال عدم التوازن بين متطلبات الموقف، وقدرة الفرد على الإستجابة لهذه المنطلبات فى المواقف العادية. يقسم "لازاروس Lazarus مصادر الضغوط الى عدة عوامل فسيولوجية وظروف بيئية

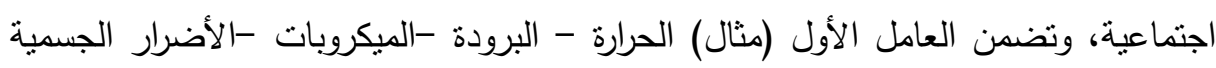

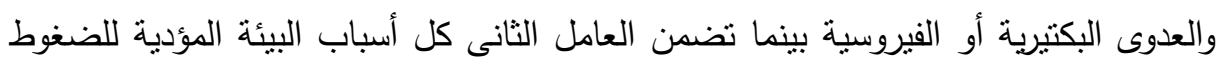

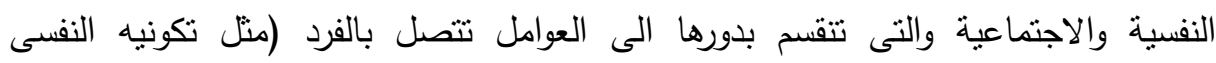
والعضوى) وعوامل بيئية واجتماعية يشترك فيها أغلب الناس. 
جمال أحمد شفيق وآخرون

وقد ميز لازاروس وكوهن Chen،Lazarus،1977 بين نوعين من الضغوط:

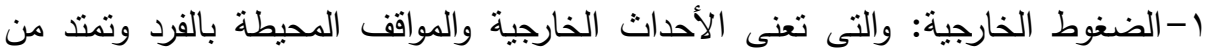

$$
\text { الأحداث البسيطة إلى الحادة. }
$$

r-الضغوط الداخلية (الثخصية) والتى تعنى الأحداث التى تتكون نتيجة التوجه الإدراكى نحو العالم الخارجى والنابع من فكر وذات الفرد. (أحمد نايل الغرير، أحمد عبد اللطيف، لإنه

$$
.(r q-r \wedge: r \cdots q
$$

وهناك العديد من المصاحبات الانفعالية التي تصاحب حدوث حدث ضاغط منها الثعور بالاستنزاف الانفعالي أو الاحتراق النفسي، زيادة المشكلات الثخصية: سرعة

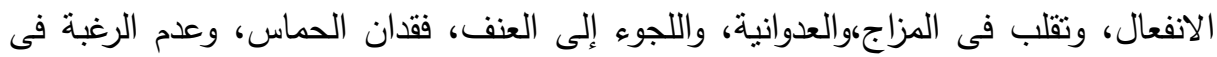

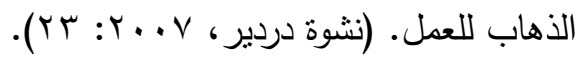

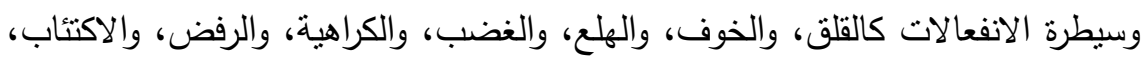

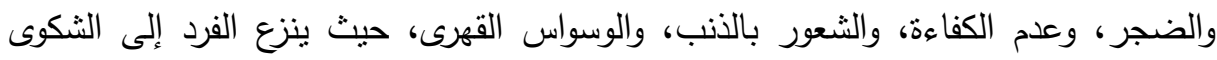

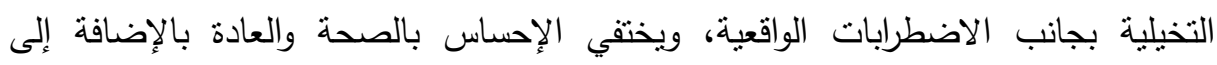

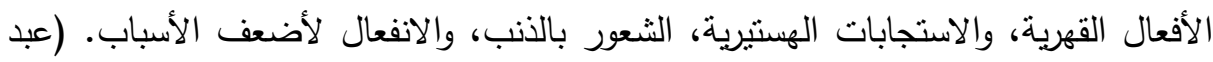

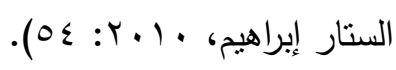

واذا كانت الدولة توجه أهتماماً لرعاية الطفولة بأعنبارها مطلباً أساسياً وهاماً لتكوين

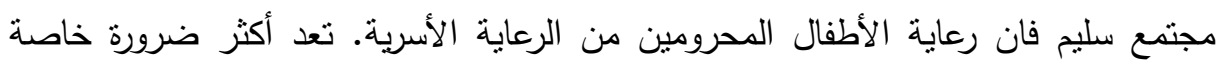
وأنهم حرموا حقهم من الرعاية في أسرهم الطبيعية والتى تعد البيئة الاساسية التى تستقبل الطفل منذ ولادته وتعاصر انتقاله من مرحلة نمو الى اخرى وعن طريقها يشبع الطفل حاجاته

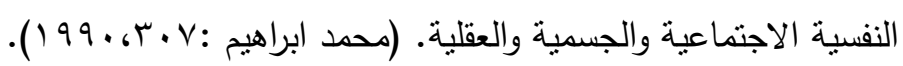

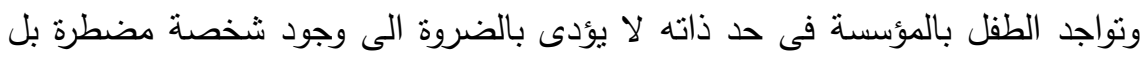

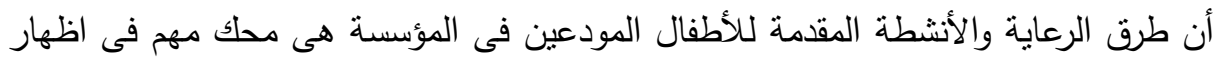

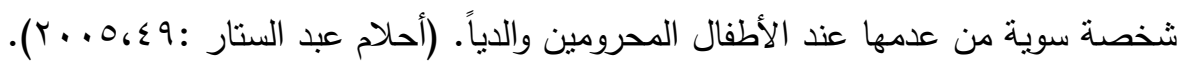


ومن المتوقع أن يكون الحرمان من الأسرة أو من الأم أو الأب له تأثثر سلبى على نمو الأطفال فى كافة جوانبه ، وينطوى على مخاطر شديدة على شخصياتهم حيث أن الحياة داخل

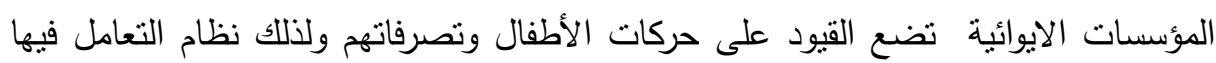

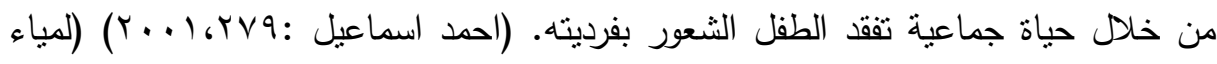

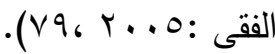

ويمر المراهق بفترات عصيية وهزات انفعالية عنيفه حيث تظهر الصراعات المعظمة والميل الى التطرف وكثرة الانفعالات ويكون المراهق حساساً نحو ذاته مدفوعاً الى الاستقلال

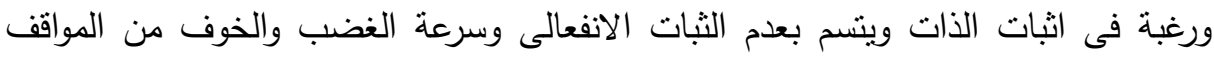

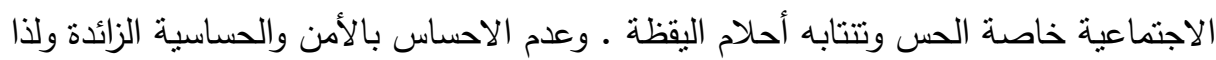

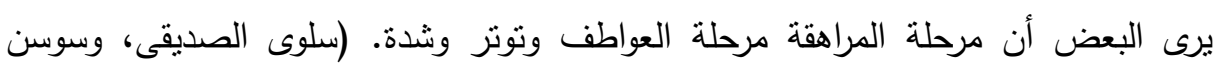

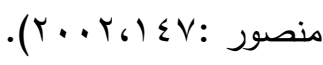
وعندما يوضع الأطفال المراهقين مجهولي النسب فى مكان ويتم عزلهم عن المجتمع، فيؤدى ذللك الى شعورهم بأنهم مختلفون عن بقية المجتمع ، وهذا قد يولد لديهم شعور بالكراهية

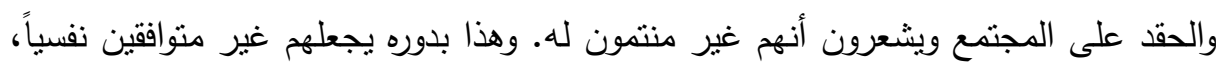
وتكون احتمالية وجود سلوك مضاد للمجتمع، وفى هذا الصدد أسفرت نتائج دراسة انسورز مارسا الى أن فقدان الثعور بالأطمئنان وعدم القدرة على التوافق مع البيئة المحيطة مما يجعل فلئل هؤلاء الأطفال أكثر عدوانية وأقل استقلالية من الأطفال الطبيعيين. Martha Ainsworth 2002،

وهذا يؤكد على أن للأسرة دوراً كبيراً فى حياة الأطفال المراهقين مجهولي النسب وان الحرمان من الدفء الاسرى يؤدى بدوره الى عدم الانتماء وينتج عنه مشاكل سلوكية مثال العدوان والتخريب وغيرها من المشكلات الأخرى. 


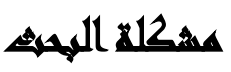

الضغوط النفسية هى الصعوبات التى تواجه الطفل المراهق مجهولي النسب وتسنتزم منه مطالب وهذه المطالب تعمل على اعاقة قدراته وامكانياته مما يؤدى الى وقوعه تحت وطأة الضغوط النفسية أو التأزم النفسى.

اهتمت الدراسات النفسية بمجال الضغوط والتي تركز على الجوانب الصحية والثخصية،

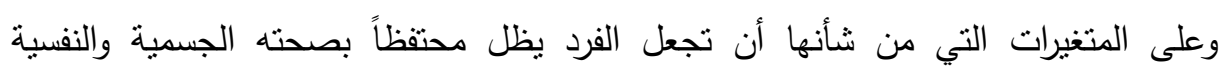

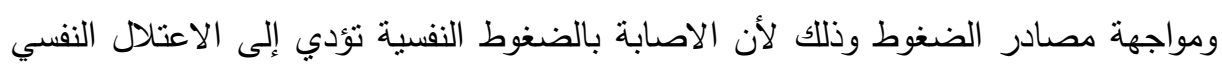
والجسمي. وعلى جانب آخر نرى أن مصادر الضغوط النفسية لدى الطفل المراهق مجهولي النسب

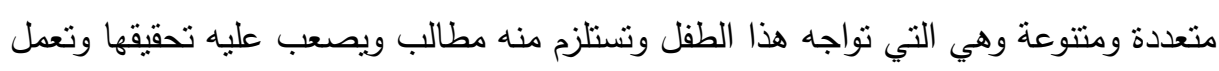

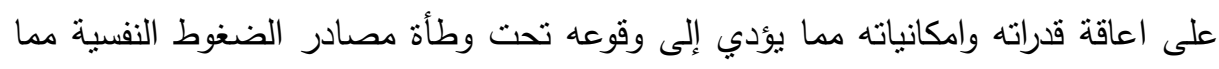

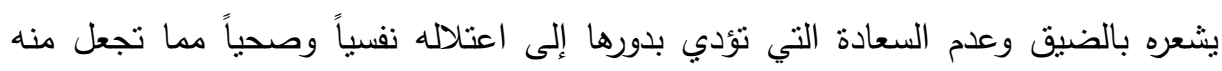
شخصاً غير منوافق مع مجتمعه. وتؤدي الأسرة دوراً كبيراً في حياة الطفل وتتشئته الاجتماعية ونموه السوي فاذا حرم هذا الطفل من الرعاية الأسرية وايداعه في احدى المؤسسات تجعله يشعر بكثير من مصنيات مصادر الضغوط وتجعل منه انسان غير سوي وتتنتر لديه الكثير من المشكلات السلوكية

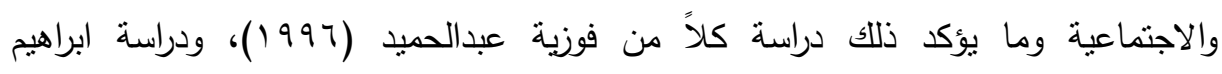

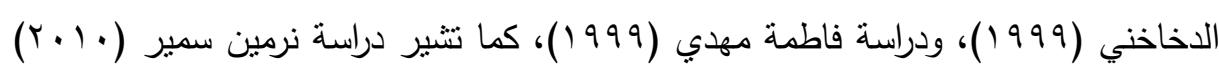
إلى أن هؤلاء الأطفال نتيجة للحرمان يشعرون بنقص الثقة بالنفس وعدم القدرة على تحمل المسئولية مما يجعلهم أكثر عرضة للاصابة بالضغولة الضغوط النفسية.

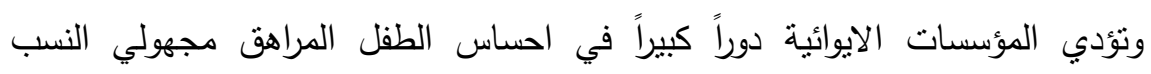

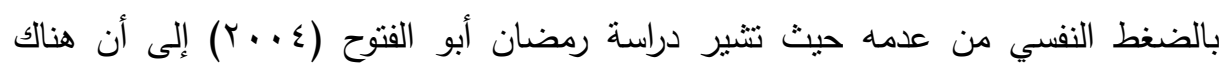

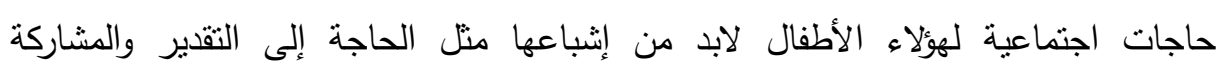

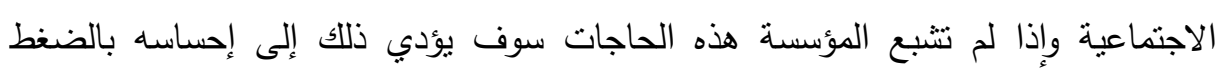

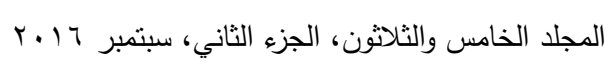


النفسي، كذلك أيضاً نتير دراسة عبلة اسماعيل ( .... إ) إلى أن المؤسسة واختيارها للاشراف

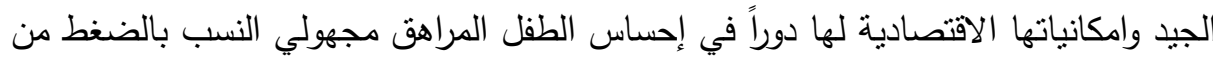

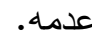

من هنا كان ولابد من التعرف على مصادر الضغوط النفسية للطفل المراهق مجهولي النسب من أجل وضع خطط للعلاج والتخفيف من هذه الضغوط أو العمل على تفادي أسبابها من أجل وقاية هؤلاء الأطفال من الاحساس بالضغوط والضيق مما بساهم ذلك في الحفاظ

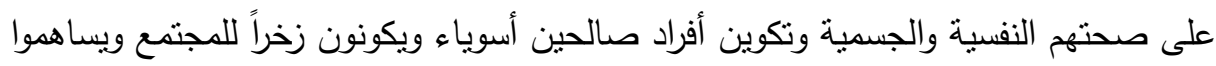
في بنائه وتقدمه.

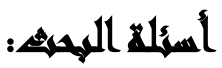

- ما مصادر الضغوط النفسية للطفل المراهق مجهولي النسب ؟

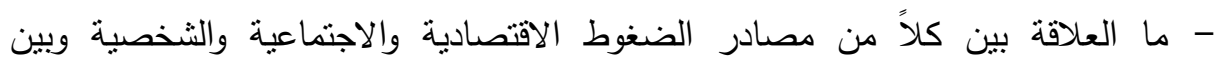
الضغوط النفسية ؟ الضعان

\section{مسوض المهAم}

التزم البحث الحالي بالحدود الآتية: الحدود الزمنية: الفترة التى استغرقها تطبيق أدوات البحث حوالى ثلاثة شهور .

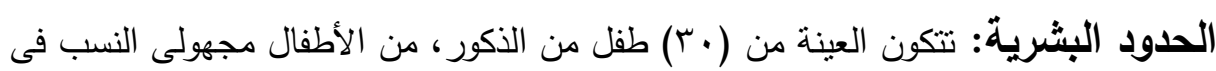

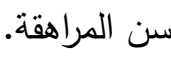
الحدود المكانية: المؤسسات الايوائية (مؤسسة انقاذ الطفولة). 


\section{أهمية المهشه}

الأهمية النظرية: تتجلى أهية هذه الدراسة من خلال طبيعة الموضوع والذي يربط بين

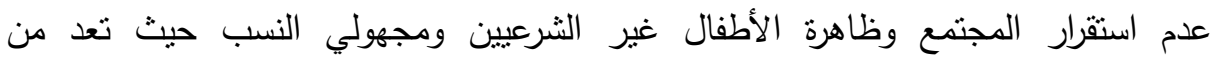

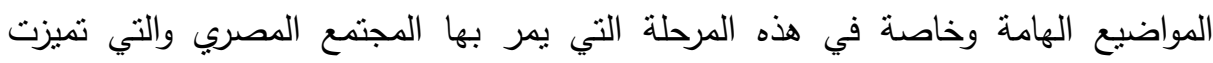

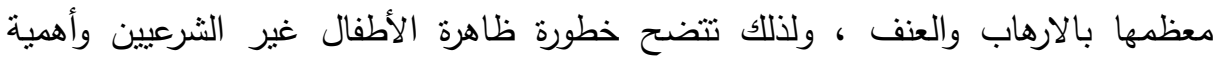
دراستها في تعدد الجوانب المرتبطة بها.

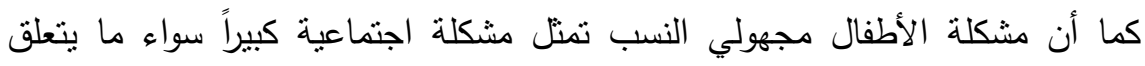

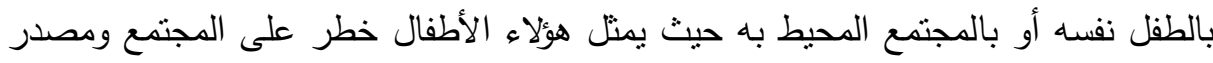

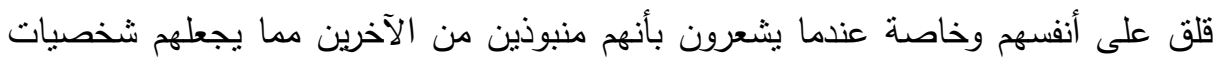
عدوانية واجرامية حاقدة وناقمة على الدجتمع ولذلك كانت أهمية دراسة هؤلاء الأطفال. الأهمية التطبيقية: ترجع أهمية هذه الدراسة من الاهنمام العالمي بهذه النوعية من الأطفال

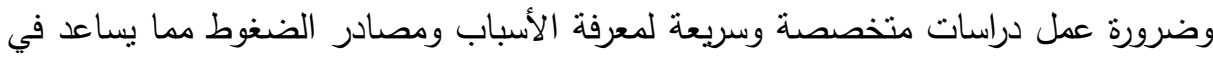
التعرف على طرق العلاج وامكانية عمل برامج تربوية علاجية لدساعدة المشرفين والمعلمين في تعديل سلوكهم.

كما تظهر أهمية الدراسة الحالية فى حيوية الجانب الذى تتتاوله من خلال التعرف على

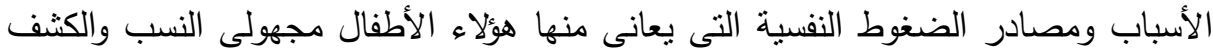
عن أهم الأبعاد النفسية لايهم سواء كانت هذة الأبعاد اجتماعية وشخصية وبيئية واقتصادية الأبادية بهدف مساعدتهم على تحقيق الثوافق النفسى الذي بساعدهم على اشباع حاجاتهم النفسية.

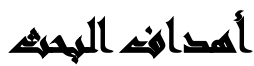

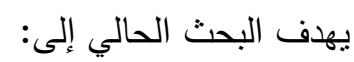

- التعرف على طبيعة الضغوط النفسية وأسبابها لدى الأطفال الدراهقين مجهولى النسب. - التوصل الى معرفة هذة الصغوط ووضع الحلول الى تخفيفها. - القاء الضوء على دور المؤسسات الايوائية لرعاية الاطفال مجهولى النسب.

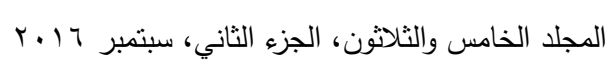


مجلة العلوم البيئية

معهد الدراسات والبحوث البيئية - جامعة عين شمس لبه

- التعرف على الخدمات التى تقدمها هذة المؤسسات الايوائية لهوُلاء الأطفال مجهولى النسب سواء كانت هذة الخدمات تعليمية أوصحية أو نفسية.

\section{هنهمج المهيد}

يستخدم البحث المنهج الوصفى والذى يعتمد على إعداد مقياس للضغوط النفسية عند هؤلاء الاطفال المراهقين مجهولى النسب فى المؤسسات الايوائية.

\section{همطللحاهي الهيهي}

الضغوط النفسية: هى مجموعة الظروف والصعوبات والمثيرات التى يواجهها الطفل فى بيئته السكنية ويتعرض لها بصفة مستمرة مما يسبب له الضيق والتوتر وينعكس هذا فى صورة اعراض نفسية وفسيولوجية واستجابات سلوكية نتجية لشعوره بعد الرضا عن السكن الذى يقيم

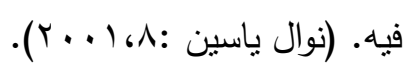

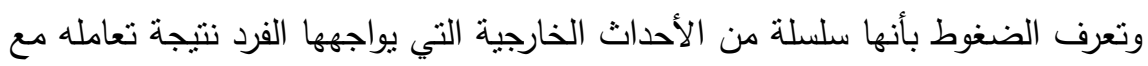
البيئة المحيطة به والتي تفرض عليه سرعة النوافق في مواجهته لهذه الأحداث لتجنب الآثار

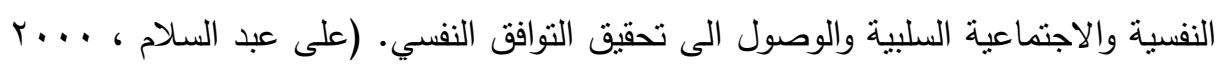

ويعرف الباحثون الضغوط النفسية اجرائياً: " بأنها مجموعة من الظروف والصعوبات الاقتصادية والاجتماعية والثخصية التي يواجهها الطفل المراهق مجهولي النسب ويتعرض لهان الها

بصفة مستمرة مما يشعره بالضيق والظلم وتظهر لديه أعراض فسيولوجيه ونفسية وسلوكية".

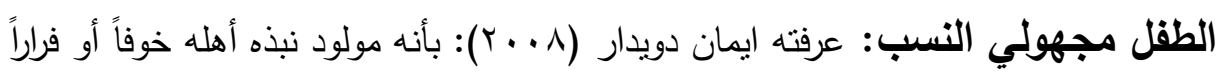

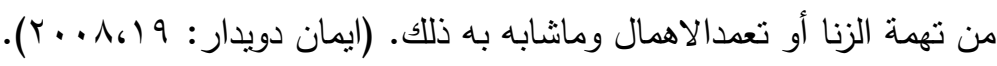

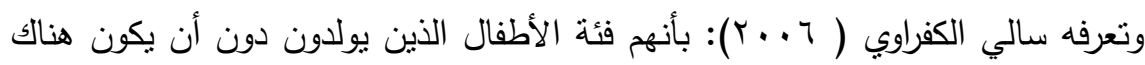

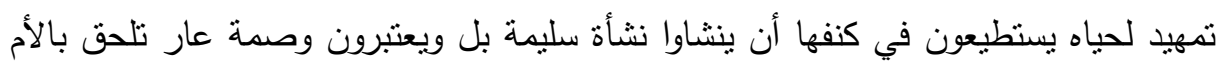

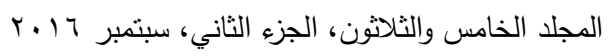


غير الثرعية ، وعلى ذلك نجدها تنتظر يوم خلاصها من هذا الطفل. (سالي الكفراوي،

.(1) : Y . . T

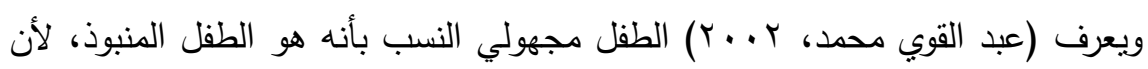

أمه نبذته وألقته في الطريق، وهو ليس الطفل الناتج عن علاقة غير شرعية بين رجل وامرأة

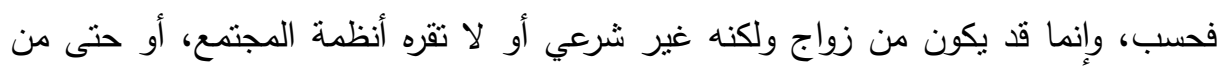

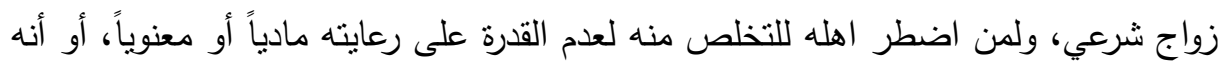
فقد أهله واستحال التحقق من نسبه، ولعل الصفة التي غلبت على اللقيط في أوساط العامة أنه النه

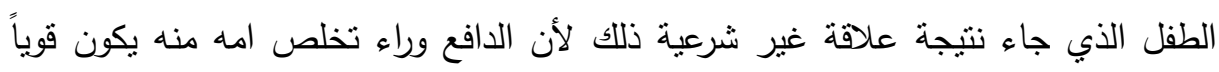
وهو الفرار من تهمة الزنا والعار ونقد المجتمع.

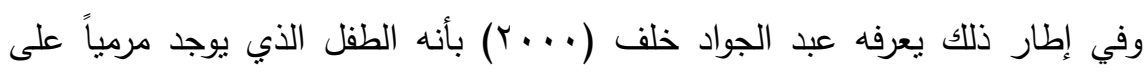
الطرق ولا يعرف أبوه وأمه. التعريف الاجرائي لطقل المراهث مجهولي النسب: - لا يعرف له كفيل، ان لم يكن له كفيل أصلاً. - أن يوجد في قارعة الطريق ويشمل أبواب المساجد ونحوها. - أن يتواجد داخل مؤسسة إيوائية ودور الرعاية ( مؤسسة انقاذ الطفولة ).

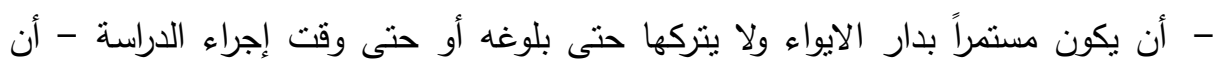

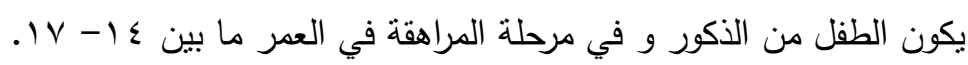
المؤسسات الايوائية: انها النمط السائد فى معظم دول العالم وتتمثل فى مؤسسة اجنماعية يوجد بها عدد من الايتام أو من فى حكهم من ذوى الظرف الخاص (مجهولي النسب) ويشرف عليهم عدد من المشرفين رجالا ونساء وكانت تسمى قديما الملاجىء وتم دنم تغيير اسمها الى دار الرعاية أوميتم وبعض دول العالم وهى قليلة مازالت تستخدم كلمة الملاجى ويجد دور المؤسسات وملاجى لصغار السن ثم ينتقلون منها الى دور خاصة بالكبار ثم دور خاصنة بالأكبر سناً تسمى فى الغالب دور الضيافة ويغلب علي هذة الدور تساوى الأعمار الأيتام

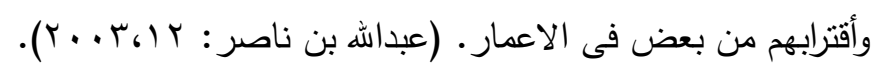

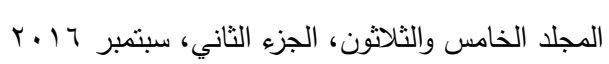


وتعرف اجرائياً: "بأنها المكان الذي يعيشون فيه الأطفال المراهقين مجهولي النسب ويتلقون الرعاية الجسمية والنفسية بداخلها وهى (مؤسسة انقاذ الطفولة)".

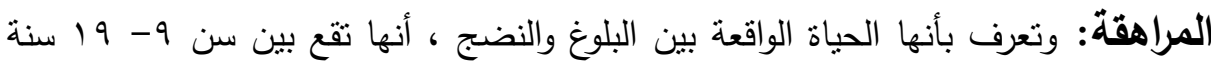

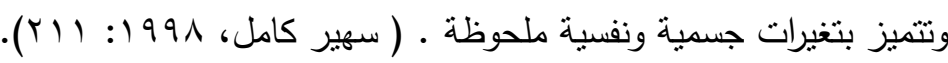

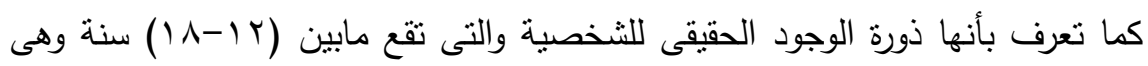
مرحلة (أزمة الهوية) وتمضى الثخص لمحصلة دنيامية للصراعات التى عاثها المراهق وهو

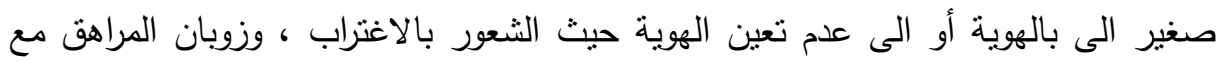

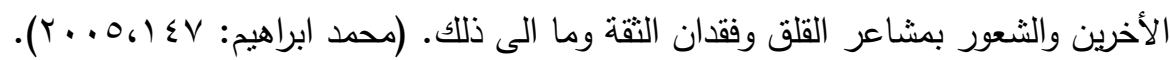

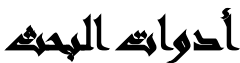

استخدمت الدراسة الحالية مجموعة من الأدوات لجمع البيانات وهي:

استبان مفتوح موجه للأطفال المراهفين مجهولي النسب: (اعداد الباحثون) وقد اشتمل الاستبيان على سؤال واحد أساسى ، وهو ما أهم المعوقات والصعوبات التي هوني تواجه الاطفال فى حياتهج؟ والهدف من هذا الاستبيان هو التعرف على مشكلات الاطفال

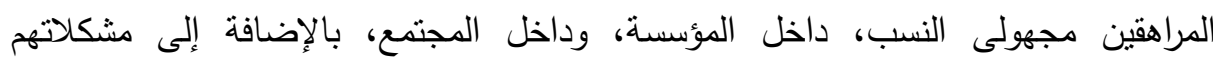
الثخصبة مما يساهم في وضع وصياغة عبارات المقياس. مقياس الضغوط النفسية للاطفال المراهقين مجهولى النسب في المؤسسات الايوائية: (اعداد الباحثون) يتكون المقياس من ثلاث أبعاد وهم الضغوط الاجتماعية بواقع (rV) عبارة، والضغوط

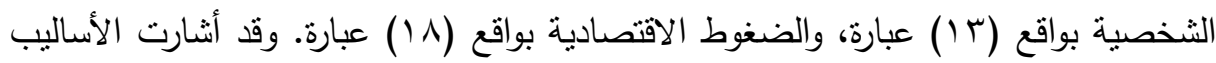
الاحصائية الي ثبات وصدق المقياس وهذا ما تشير اليه الجدوال التالية. 


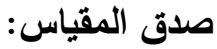

جدول (1): صدق الاتساق الداخلي لأبعاد مقياس الضغوط النفسية

\begin{tabular}{|c|c|c|c|}
\hline معامل الارتباط & إجمالي المقياس & \multicolumn{2}{|c|}{ أبعاد المقياس } \\
\hline \multirow{2}{*}{$\cdot, 91$} & $\left({ }^{(* *)} \cdot, 974\right.$ & معامل ارتباط بيرسون & \multirow{2}{*}{ الضغوط الاجتماعية } \\
\hline & $\cdot, \cdots 1$ & الدلالة المعنوية & \\
\hline \multirow{2}{*}{$\cdot, 91$} & $\left({ }^{* *}\right) \cdot, \wedge \varepsilon 1$ & معامل ارتباط بيرسون & \multirow{2}{*}{ الضغوط الثخصية } \\
\hline & $\cdot, \cdots 1$ & الدلالة المعنوية & \\
\hline \multirow{2}{*}{$\cdot, V r$} & $\left({ }^{*}\right) \cdot, 0 \mathrm{VV}$ & معامل ارتباط بيرسون & \multirow{2}{*}{ الضغوط الاقتصادية } \\
\hline & $\cdot, \cdot r$ & الدلالة المعنوية & \\
\hline
\end{tabular}

من جدول صدق الاتساق الداخلي السابق للمقياس نجد أن معامل ارتباط أبعاد المقياس

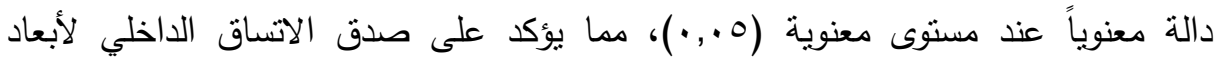

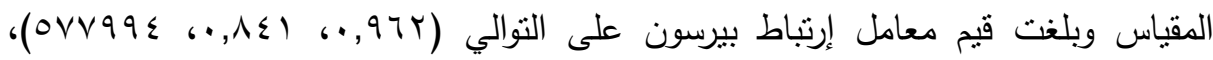
وللمزيد من التحليل قام الباحث بحساب معامل الارتباط المصحح التي بلغت قيمه بالترنيب ( ) ثبات المقياس: للتحقق من ثنات مقياس الضغوط النفسية للأطفال المراهقين استخدم الباحث معادلة ألفا كرونباخ (Cronbach Alpha)، ويوضح الجدول التالي معاملات الثبات الناتجة

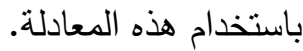
جدول(r): ثبات العبارات لأبعاد مقياس الضغوط النغان النفسية

\begin{tabular}{|c|c|c|}
\hline قيمة ألفا & عدد العبارات & آبعاد المقياس \\
\hline$\cdot, \vee \vee 91$ & $r V$ & الضغوط الاجتماعية \\
\hline$\cdot, 7 \times 1$ & $\pi$ & الضغوط الثخصية \\
\hline., 044 & 11 & الضغوط الاقتصادية \\
\hline$\cdot, \wedge Y q$ & 01 & إجمالي المقياس \\
\hline
\end{tabular}

يتضح من الجدول السابق أن قيم معاملات الثبات جميعها قيم مقبولة حيث بلغت قيم

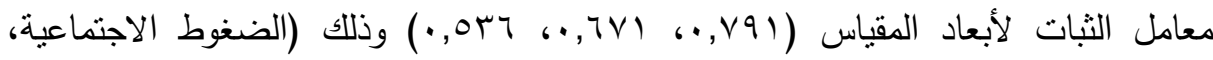

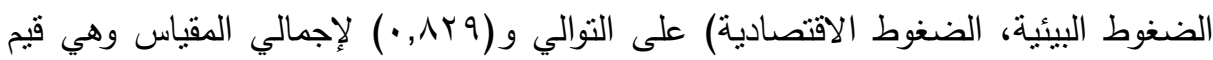


ذات ثبات مقبولة لإرتفاعها عن (0,·) وتتشير هذه القيم إلى صلاحية المقياس للنطبيق وإمكانية الاعتماد على نتائجه والوثوق به. استمارة جمع البيانات الاولية: وقد اشتملت على البيانات الديموخرافية وهى :الأسم، السن، النوع، الحالة الاجتماعية، اسم المؤسسة.(إعداد الباحثون).

\section{إلجراعايت المبهث}

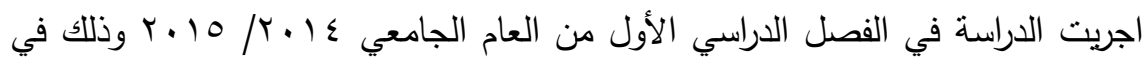
شهور أكتوبر ، ونوفمبر ، وديسمبر ، وأجريت الدراسة بمؤسسة انقاذ الطفولة بالألف مسكن القاهرة - ماه

وتم إجراء الدراسة على عينة قوامها (•r) طفل من الأطفال المراهقين مجهولي النسب

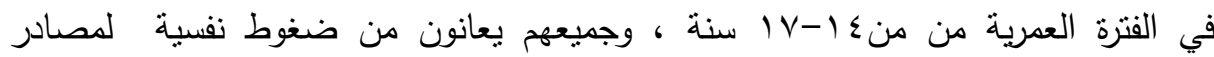
مختلفة. خصائص عينة البحث: جدول رقم(ب): الاطفال سن (ع ا-0 1) سنة

\begin{tabular}{|c|c|c|c|c|c|}
\hline المكان & التعليمية & الصحية & الاجتماعية & النوع & عد ع الأطفال \\
\hline جمعية أنقاذ & الاعدادية & جيدة & مجهولى النسب & ذكر & 17 \\
\hline
\end{tabular}

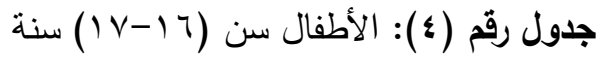

\begin{tabular}{|c|c|c|c|c|c|}
\hline المكان & التعليميلة & الصحالة & الاجتماعية & النوع & عدن الاطفال \\
\hline جمعِة أنقاذ & الثانوية & جيدة & مجهولى النسب & ذكر & $1 \varepsilon$ \\
\hline
\end{tabular}

نم تطبيق الاستبيان المفتوح الموجه للأطفال المراهقين مجهولي النسب وكان يحتوي على : ملى

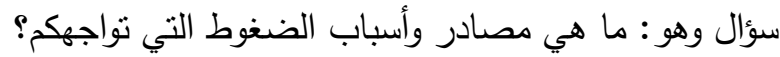
- ومن خلال استجابات الأطفال تمت صياغة بنود وعبارات المقياس بحيث تغطى محاور وأبعاد مقياس الضغوط النفسية للاطفال المراهقين مجهولى النسب. 
- تم تحديد المقياس حيث يكون النطبيق بطريقة فردية ،كل طفل على حدة، ويقوم الطفل بتطبيقه بنفسه.

- عرض المقياس على عدد من الأساتذة المحكمين بهدف التأكد من صلاحيته وشموله، بلهة ملائمنه للاطفال مجهولى النسب، والتاكيد من دقة الصياغة ووضوحه. - وتم تعديله بناء على آراء السادة المحكمين وتمت صباغته في صورته النهائية.

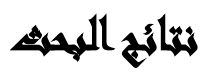

سوف يتم عرض نتائج الدراسة ومناقثتها للتعرف على مصادر الضغوط النفسية للأطفال المراهقين مجهولى النسب فى ضوء نساؤل الدراسة:

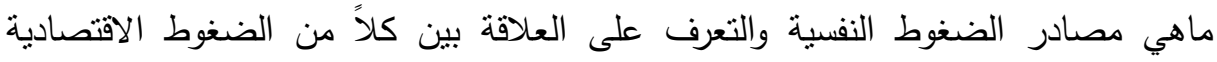
والثخصية والاجتماعية وبين الضغوط النفسية للطفل المراهق مجهولى النسب فى المؤسسات

الايوائية؟

الفرض الأول: الكثف عن طبيعة العلاقة بين الضغوط الاجتماعية والضغوط النفسية للطفل المراهق مجهول النسب في المؤسسات الإيوائية. جدول(ه): العلاقة بين الضغوط الاجتماعية والضغوط النفسية

\begin{tabular}{|c|c|c|}
\hline لضغوط النفسية & & \\
\hline$(" *) \cdot, 90 \leqslant$ & معامل الارتباط & \multirow{2}{*}{ الضغوط الاجتماعية } \\
\hline$\cdot, \cdots 1$ & المعنوية & \\
\hline
\end{tabular}

بالنظر في الجدول السابق ينضح وجود علاقة ارتباطية ذات دلالة معنوية عند مستوى معنوية (0., •) بين الضغوط الاجتماعية والضغوط النفسية حيث بلغت قيم الدلالة المعنوية

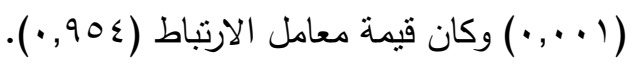

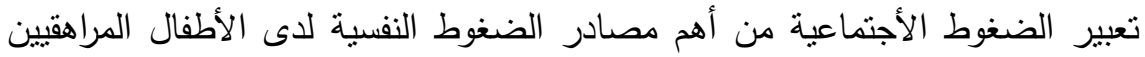
مجهولى النسب ويظهر من خلال النسب المئوية لعبارات النى تعبير عن هذة الضغوط 
مجلة العلوم البيئية

معهد الدراسات والبحوث البيئية - جامعة عين شمس لئس

حيث نرى أن مثل هذة الضغوط الاجتماعية والتى تئدى بدورها الى شعور هؤلاء الاطفال المراهقيين مجهولى النسب بالحرمان والامان الأسرى والدف والذى يتمتع بها الأخرين. كما أن هؤلاء الأطفال يجدون صعوبة فى تكوين علاقات أجتماعية جيدة من المحطيين بهم سواء فى المدرسة أو خارج المؤسسة. ويؤكد ذلك ما أشنارت اليه نتائج دراسة (جمال شحاته - 1990 () فى أن الأطفال فى ألى المؤسسات الايوائية غير قادرين على اقامة علاقات اجتماعية مع الاخرين. 
جمال أحمد شفيق وآخرون

جدول(†): الأعداد والنسب لإجابات عينة الدراسة لمقياس الضغوط النفسية (الضغوط

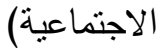

\begin{tabular}{|c|c|c|c|c|c|c|c|}
\hline \multicolumn{2}{|c|}{ ע } & \multicolumn{2}{|c|}{ أحيانًاً } & \multicolumn{2}{|c|}{ نعم } & \multirow{2}{*}{ 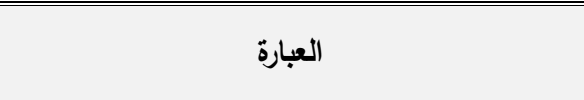 } & \multirow[b]{2}{*}{ b } \\
\hline$\%$ & عدد & $\%$ & عدد & $\%$ & عدد & & \\
\hline - & - & $14, \mathrm{~V}$ & • & Ar,r & ro & اشعر بالحزن لعدم وجود أحد يسأل علينا فى العدى العدين & 1 \\
\hline A. & Y & $\curlyvee, \mathrm{V}$ & r & ir,r & $\varepsilon$ & أخشى التعامل مع الأخرين خارج المجتمع المحيط & r \\
\hline 9. & rv & $r, r$ & 1 & $\curlyvee, \mathrm{V}$ & r & أجد صعوية فى اقامة علاقات جيدة مع زملائى & r \\
\hline - & . & ץ & 11 & ז,r & 19 & أخجل من زيارة زميل لى فى السكن وذلك لوجودى & $\varepsilon$ \\
\hline . & . & $74, \mathrm{~V}$ & $r \cdot$ & $r \mu, r$ & 1. & أخجل من المسكن اللى أنا عايش فيه & o \\
\hline$\neg, \mathrm{V}$ & r & 7. & 11 & r & 1. & بحلم أن كل الحاجات اللى مع زملائى تبقى بتعتى & 1 \\
\hline $14, \mathrm{~V}$ & - & ๑. & 10 & r r & 1. & ساعات اخذ حاجة زملائى من دوالبيهم من غير ما & $\mathrm{v}$ \\
\hline$r, r$ & 1 & $\Lambda \mu, r$ & ro & ir,r & $\varepsilon$ & عايز أخرب الحاجات اللى فى المؤسسة & $\Lambda$ \\
\hline 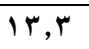 & $\varepsilon$ & $r \mu, r$ & $\mathrm{v}$ & r & 19 & كثير كنت أروح للمشرفين علثان أخذت حاجة غيرة & 9 \\
\hline Ir, r & $\varepsilon$ & A. & $r \varepsilon$ & $7, \mathrm{~V}$ & r & لما بكون زعلان لازم أخرب كل حاجة بشوفها & 1. \\
\hline$r r, r$ & 1. & $\varepsilon r, r$ & it & $r r, r$ & $\mathrm{v}$ & لما المشرفين بيزعلونى بيقى عايز أخرب حاجتى & 11 \\
\hline - & . & 7. & 11 & 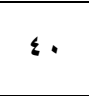 & ir & المجتمع اللى انا فيه مش عاوزنى، وأنا أيضًا مش & ir \\
\hline - & . & or, r & 17 & $\leqslant 4, \mathrm{~V}$ & $1 \varepsilon$ & أصحابى لما بييوظوا حاجتى لازم أبوظ حاجتهم & Ir \\
\hline - & - & v. & ri & r. & 9 & أغضب عندما يسألنى أحد عن منزلى أو أسرتى & $1 \leqslant$ \\
\hline$r, r$ & 1 & $r 4, v$ & 11 & 7. & 11 & بأخذ حقى بالقوة والضرب & 10 \\
\hline$\cdot$ & $\cdot$ & o. & 10 & o. & 10 & دائمًا أسال نفسى مين أهلى ولماذا تركونى؟ & 17 \\
\hline$\wedge$. & $r \leq$ & $\cdot$ & $\cdot$ & $r \cdot$ & 7 & أصدقائى كلهم من المؤسسة & iv \\
\hline$r, r$ & 1 & $9 r, r$ & rA & $r, r$ & 1 & لااحب المشرفين داخل المؤسسة & 11 \\
\hline $1 \Gamma, r$ & $\varepsilon$ & 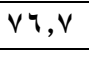 & $r r$ & 1. & $r$ & لألثشعر بالأمان وأنـا نائم & 19 \\
\hline . & . & $1 \pi, r$ & $\varepsilon$ & $\Lambda \uparrow, \vee$ & rq & خجل من معرفة المدرسين أنى من المؤسسة & r. \\
\hline . & - & $r$ r. & 1 & A. & $r \varepsilon$ & ايوجد أحد داخل المؤسسة يهتم بى & ri \\
\hline
\end{tabular}




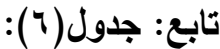

\begin{tabular}{|c|c|c|c|c|c|c|c|}
\hline \multicolumn{2}{|c|}{ ע } & \multicolumn{2}{|c|}{ أحيانًا } & \multicolumn{2}{|c|}{ نعم } & \multirow{2}{*}{ 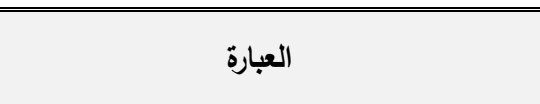 } & \multirow[b]{2}{*}{ b } \\
\hline$\%$ & عدد & $\%$ & عدد & $\%$ & عدد & & \\
\hline - & - & r, r & 1 & $94, \mathrm{~V}$ & rq & أكره أن يهيننى أو يعتدى عليا احد باللفظ داخل & r \\
\hline . & . & 1. & $r$ & 9. & $\overline{r v}$ & اشعُ بالظلم من ادارة المؤسسة & r \\
\hline . & . & o. & 10 & o. & 10 & اكره تدخل أمن المؤسسة في شئوني & $r \leqslant$ \\
\hline$r$ r. & 7 & $\mathrm{v}$. & ri & 1. & $r$ & أثشعر بالضيق والقلق عندما أكون وحيدًا & ro \\
\hline$r, r$ & 1 & $94, v$ & rq & . & . & لايا أحساس بأنى منبوذ من الناس & Y4 \\
\hline 1. & $r$ & vr,r & rr & $14, \mathrm{~V}$ & • & أتبع الفوضى داخل المؤسسة وأسبب الكثير من & rV \\
\hline
\end{tabular}

الى أن التكرارات والنسب المئوية لعبارات (الضغوط الاجتماعية) لمقياس الضغوط

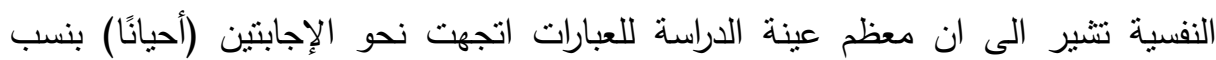

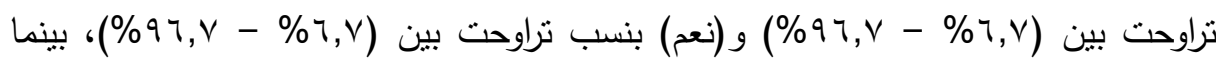

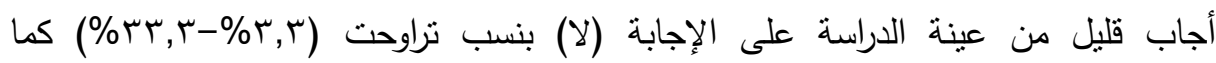
بالجدول أعلاه.

ويتبن أيضاً ان أكثر من (r^) طفل من أصل (•r) طفل وهى عينة الدراسة يعانون من الضغوط الاجتماعية والتى تؤدى بهم الى أصابتهم بالضغوط الضن النفية.

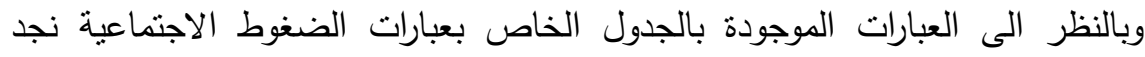

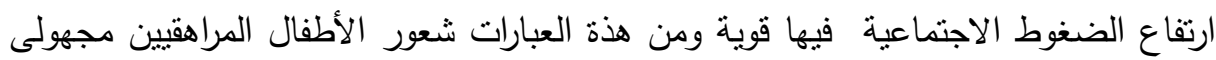
النسب بعدم وجود أحد يسأل عليهم فى المدرسة حيث بلغت حوالى (Y0) طفل من اجمال

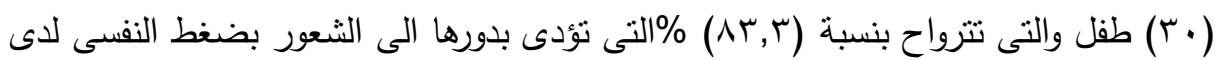

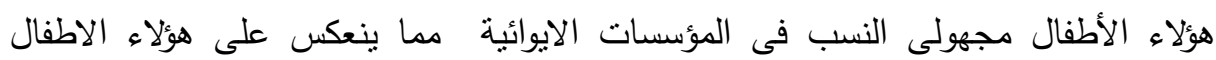
بالحزن والتعاسة داخل المؤسسة. كما نلاحظ أن نسبة (9 1) طفل من اجمالى (•r) طفل اجمالى عينة الدراسة بشعرون

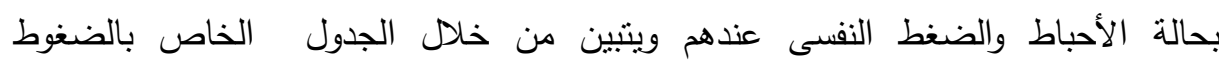

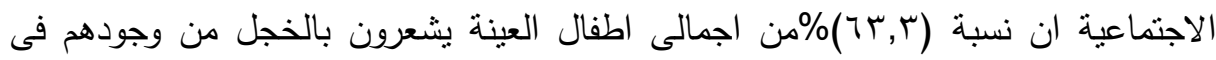


المؤسسة ومن معرفة زملاءهم فى المدرسة أنهم اطفال مجهولى النسب ويعيشون فى المؤسسات الايوائية وهذا بدورها يؤدى الى شعورهم بالضغوط النفسية ـ كما نلاحظ ان نسبة

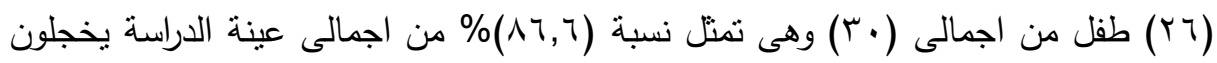
من معرفة المدرسين فى المدرسة بأنهخ أطفال مجهولى النسب ويعيشون فى المؤسسات الايوائية وهذا بدوره يؤدى الى ضغوط نفسية لديهم ويشعرون بحالة نفسية سئية لمعرفة المدرسين اصلهم أنهم اطفال مؤسسات ايوائية.

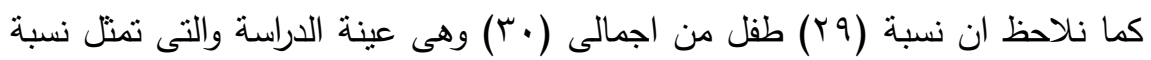

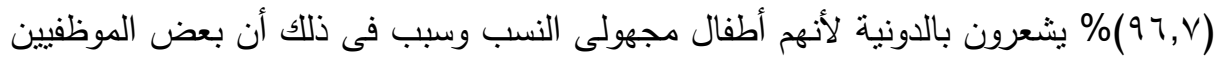
داخل هذه المؤسسات يعاملون هؤلاء الاطفال يشكل مهين كما برى هؤلاء الاطفال أن ادراة المؤسسات الايوائية تعاملهم بظلم وعدم اخذ حقوقهم واحتياجاتهم منها. وبشكل اجمالي نرى ان الضغوط الاجتماعية تكون سببا في الاحساس بالضغوط الضوانها النفسية وان المستوى الاجتماعي والثقافي المتدني للمؤسسة تكون سببا في شعور هؤلاء اطفال

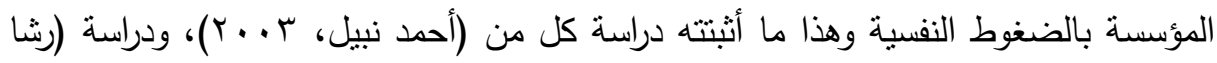

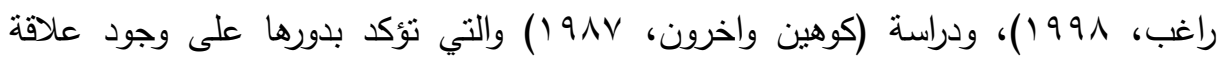
عكسية بين المستوى الاقتصادي والاجتماعي وبين الثعور والاحساس بالضغوط النفسية. الفرض الثانى: الكثف عن العلاقة بين الضغوط الثخصية والضغوط النفسية عند الأطفال المراهقين مجهولى النسب فى المؤسسات الايوائية. جدول(V): العلاقة بين الضغوط الثخصية والضغوط النفسية

\begin{tabular}{|c|c|c|}
\hline الضغوط النفسية & & \\
\hline${ }^{(* *)} \cdot, \lambda r \mu$ & معامل الارتباط & \multirow{2}{*}{ الضغوط الشخصية } \\
\hline$\cdot, \cdots 1$ & المعنوية & \\
\hline
\end{tabular}

بالنظر في الجدول السابق يتضح وجود علاقة ارتباطية ذات دلالة معنوية عند مستوى معنوية (0., •) بين الضغوط البيئية والضغوط النفسية حيث بلغت قيمة الدالالة المعنوية

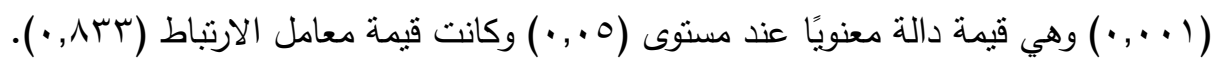


تعتبر الضغوط الثخصية من اهم المصادر التى نؤدى الى الثعور بالضغوط النفسية لوجود علاقة ارتباطية مابين الضغوط الثخصية وبين الضغوط النفسية وبملاحظة العبارات الخاصنة بالضغوط الشخصية الموجودة فى الجدوال رقم (^). جدول(^): الأعداد والنسب لإجابات عينة الدراسة لمقياس الضغوط النفسية (الضغوط

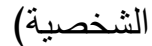

\begin{tabular}{|c|c|c|c|c|c|c|c|}
\hline \multicolumn{2}{|c|}{$y$} & \multicolumn{2}{|c|}{ 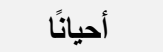 } & \multicolumn{2}{|c|}{ نعم } & \multirow{2}{*}{ 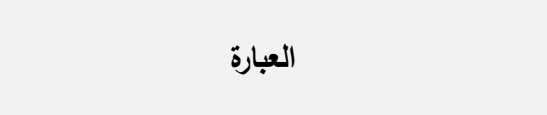 } & \multirow{2}{*}{ p } \\
\hline$\%$ & عدد & $\%$ & عدد & $\%$ & عدد & & \\
\hline . & . & $r \mu, r$ & v & $V_{4}, \mathrm{~V}$ & rr & أشعر بالضيق من وجودى فى المؤسسة & 1 \\
\hline . & . & $04, \mathrm{~V}$ & IV & \& & $1 \%$ & أتمنى أن أنتقل للسكن فى مكان أخر & r \\
\hline$r, r$ & 1 & $\wedge$. & $r \varepsilon$ & $17, \mathrm{~V}$ & $\bullet$ & لما بكون زعلان أخرب كل حاجة بشوفها & $r$ \\
\hline$\checkmark, \mathrm{V}$ & $r$ & r & 19 & $r$. & 9 & على طول أثوف حاجة غيرى أحسن من حاجتى & $\varepsilon$ \\
\hline$r, r$ & 1 & r & 19 & rr,r & 1. & بيقى فرحان وأنا بكلب على أصحابى & 0 \\
\hline$r, r$ & 1 & q. & rv & $\neg, V$ & r & أحتقر نفسى لأنى طقل مجهول النسب & 4 \\
\hline . & . & 7. & 11 & $\varepsilon$ & ir & لا أثُعر أن المؤسسة هى بيتى الحقيقة وأتمنا ان & $v$ \\
\hline$\Lambda r, r$ & ro & $r, r$ & 1 & ir,r & $\varepsilon$ & أجد صعوية فى التعامل مع الأخرين & $\wedge$ \\
\hline $7, \mathrm{~V}$ & $r$ & o. & 10 & $\varepsilon r, r$ & ir & لا أحب أن أكون مسئول عن نفسى & 9 \\
\hline . & . & 9 १४ $\vee$ & rq & $r, r$ & 1 & مواعيد الأكل غير مناسبة لى & 1. \\
\hline . & . & ๑ , V & iv & $\varepsilon r, r$ & ir & أنا غير قادر على أخذ قراراتى لوحدى & 11 \\
\hline - & - & 1. & $r$ & q. & rv & أشعر بسوء معاملة العاملين لنا داخل المؤسسة & ir \\
\hline - & . & $r r, r$ & v & V४, & rr & أثثعر بالاحباط لتحم العاملين فينا لأننا أطفال & ir \\
\hline
\end{tabular}

يتضح لنا أن التكرارات والنسب المئوية لعبارات (الضغوط الثخصبة) لمقياس الضغوط

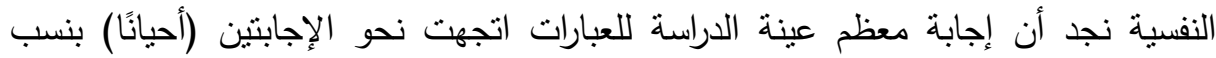

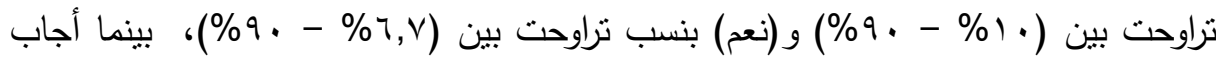




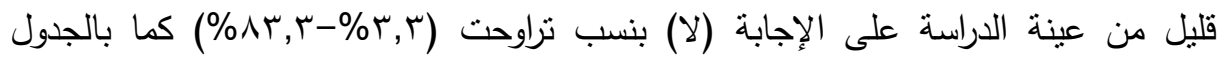

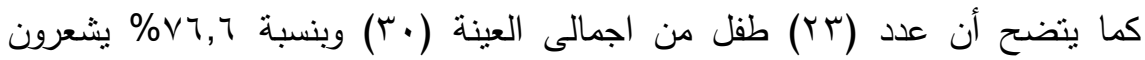
بالضيق من وجودهم داخل هذة المؤسسات الايوائية وان هذا المؤسسة ليست بيتهم الحقيقى

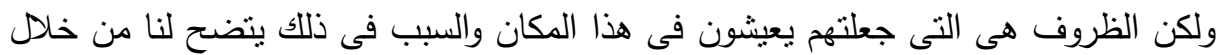

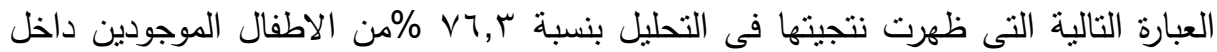

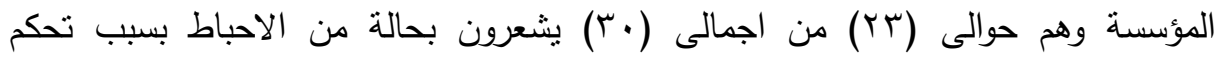

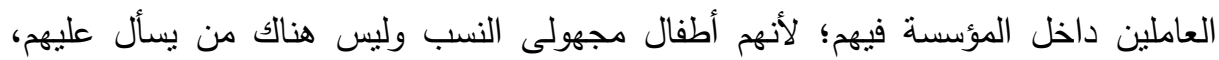
وعدم اتخاذ اجراءات من ادراة المؤسسة ضد هؤلاء العاملين. وتتفق دراسة (جمال شحاته، لألهال

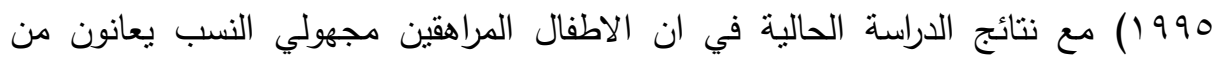

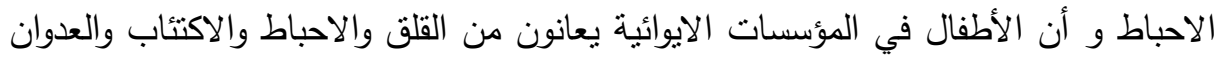

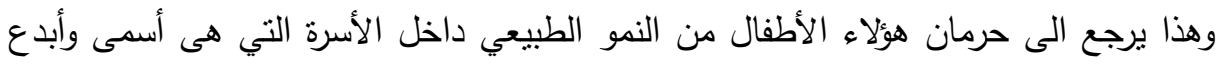

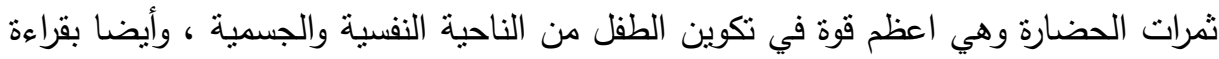

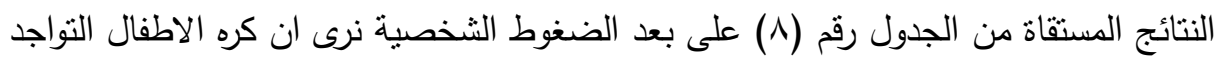

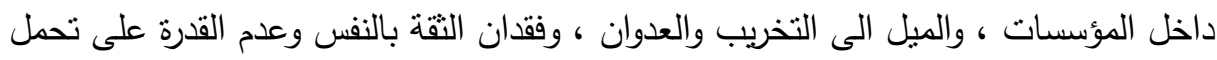
المسئولية والميل الى الكذب قد حصلت على درجات مرتفعة مما يشير الى ظهور وانتشار

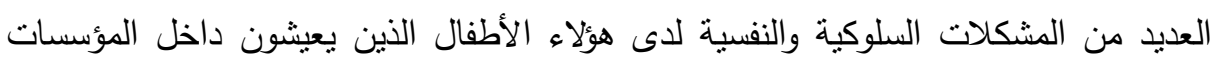

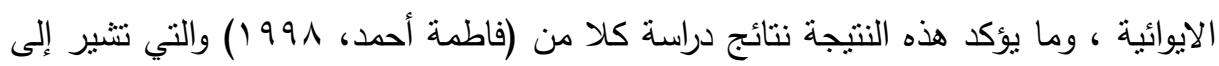

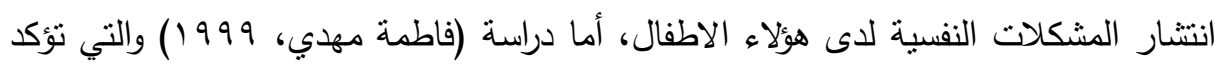
على أن الطفل الذي بعيش بالمؤسسات الايوائية بعانى من العدوان ونمو ذات التهات سلبي، كما تؤكد

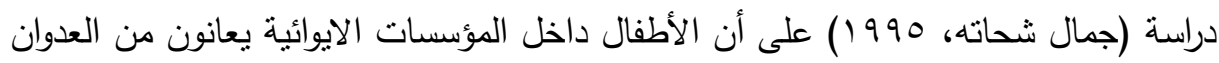

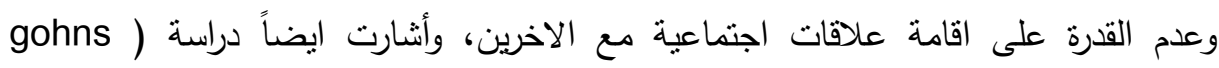

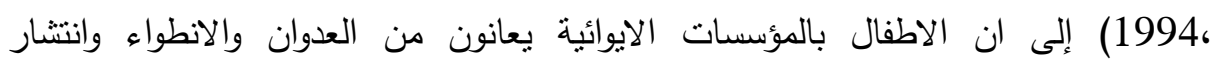

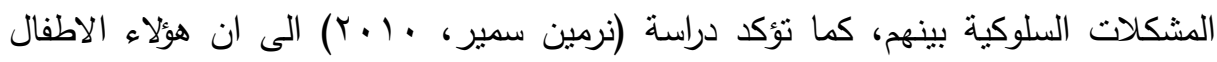

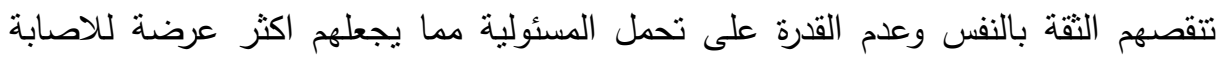

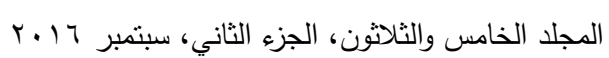


بالضغوط النفسية ، وعلى الاجمال نرى أن الضغوط الثخصية تؤدى الى الاحساس بالضيق وبالثعور بالضغط النفسي.

وتؤكد نظرية (موراى) ان هناك مجموعة من الاحتياجات يحاول الاطفال المراهقين مجهولى النسب فى الحصول عليها مثل: الحاجات الاولية (الغذاء والجنس) وهناك احتاجات أخرى مثل (الانتماء - الاستقلال - الدفاعية) وتتفق معها دراسة (رمضان أبو الفتوح، ع . . Y)، واذا لم تشبع هذه الحاجات سوف يشعرون بالضغوط النفسية، وبقراءة النتائج الجدول رقم (^) الخاص بالبعد الضغط الثخصى نرى انهم يكرهون ان يعتدى عليهم احد باللفظ داخل المؤسسة بنسبة (r,7 9) ويؤدى ذلك الى الدفاعية وهى الدفاع عن الذات فى مواجهة الاهانة، والاستقلال الذاتى فى الحصول على الحرية والتخلص من تدخل الادراة وبعض الموظفين فى شُونهم.

الفرض الثالث: الكشف عن العلاقة بين الضغوط الاقتصادية والنفسية عند الأطفال المراهقين مجهولى النسب فى المؤسسات الايوائية.

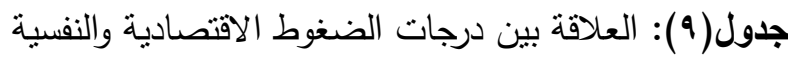

\begin{tabular}{|c|c|c|}
\hline لضغوط النفسية & & \\
\hline$\left({ }^{* *}\right) \cdot, \leq 9$. & معامل الارتباط & \multirow{2}{*}{ الضغوط الاقتصادية } \\
\hline$\cdot, \cdots 7$ & المعنوية & \\
\hline
\end{tabular}

بالنظر في الجدول السابق يتضح وجود علاقة ارتباطية ذات دلالة معنوية عند مستوى معنوية (0. . •) بين الضغوط الاقتصادية والضغوط النفسية حيث بلغت قيمة الدلالة المعنوية

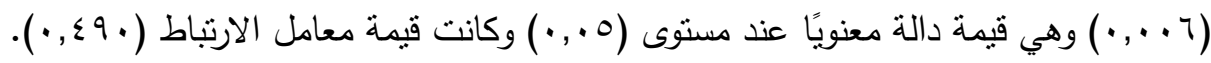
وان الظروف الاقتصادية التى تعانى منها المؤسسات الايوائية ونقص الامكانيات المادية

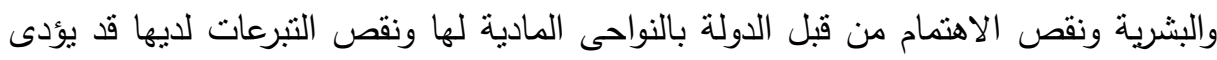

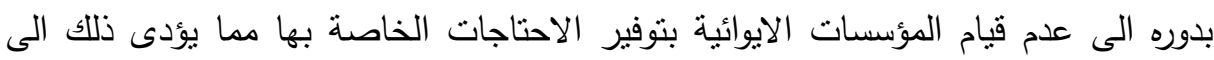
ضغوط نفسية على هؤلاء الاطفال مجهولى النسب فى هذة المؤسسات الايوائية. وما يؤكد على ان الضغوط الاقتصادية تؤدي الى الثعور بالضيق النفسي دراسة (جمال

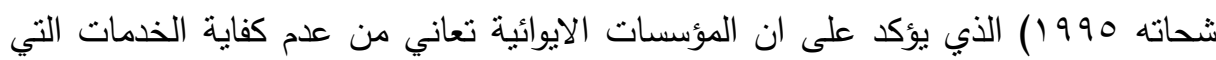


تقدها، كما تؤكد دراسة (رشا راغب 1991) بان المستوى الاقتصادي ونقص الامكانيات

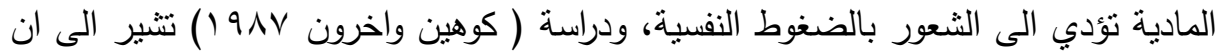
تذني المستوى الاقتصادي يؤدي الى الشعور بالضغوط النفسية. جدول(• (1): الأعداد والنسب لإجابات عينة الدراسة لمقياس الضغوط لإس النفسية (الضغوط الاقتصادية)

\begin{tabular}{|c|c|c|c|c|c|c|c|}
\hline \multicolumn{2}{|c|}{ ע } & \multicolumn{2}{|c|}{ أحيانًا } & \multicolumn{2}{|c|}{ نعم } & \multirow{2}{*}{ 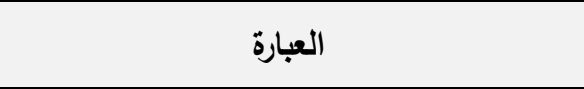 } & \multirow[b]{2}{*}{ b } \\
\hline$\%$ & عدد & $\%$ & عدد & $\%$ & عدد & & \\
\hline . & . & - & $\cdot$ & $1 \ldots$ & $r$ r. & لا يتوفر لى مكان مناسب للمذاكرة & 1 \\
\hline . & $\cdot$ & $94, \Gamma$ & YA & $7, \mathrm{~V}$ & r & أكره الكل في المؤسسة & $r$ \\
\hline . & - & r. & 9 & $\mathrm{v} \cdot$ & r) & عدم الاهنمام بمكان النوم & r \\
\hline . & - & $7, \mathrm{~V}$ & r & $94, r$ & ra & مصروفى غير كافى & $\varepsilon$ \\
\hline . & . & $\bar{Y} 4, \mathrm{Y}$ & $\Lambda$ & $\overline{V T, T}$ & TY & أكره اللبس لأنه متثابه مع زملائي بالمؤسسة & 0 \\
\hline . & . & $\varepsilon r, r$ & 14 & $07, \mathrm{~V}$ & IV & لا توجد أنشطة داخل المؤسسة & 7 \\
\hline . & . & $r$. & 7 & A. & $r \varepsilon$ & أحب أن تكون هناك حجرة خاصة بى & $\mathrm{V}$ \\
\hline - & • & $\sum 4, \mathrm{~V}$ & $1 \varepsilon$ & Or, r & 17 & أجد صعوبة في الحصول على إحتباجاتى & $\wedge$ \\
\hline · & - & זr, & 19 & r & 11 & أحب أن أحصل على ملآبس جديدة مثل زملائى & 9 \\
\hline r,r & 1 & r, ז & 1 & $9 \pi, r$ & rی & 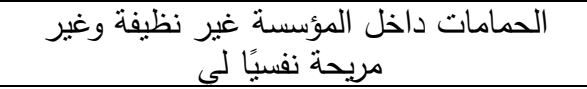 & 1 . \\
\hline . & . & . & . & $1 \ldots$ & $r$. & الدواليب والسراير داخل المؤسسة قديمة جدًا & 11 \\
\hline . & . & $V T, r$ & r & $Y 7, \mathrm{~V}$ & $\Lambda$ & ع أحب أن أجد أهلى مثل باقى الناس العاديين & IT \\
\hline$\cdot$ & $\cdot$ & $77, V$ & $r \cdot$ & ru, & 1. & أحب أن يكون داخل المؤسسة طبيب خاص لينا & $1 T$ \\
\hline$r, r$ & 1 & Ir, & $\varepsilon$ & $\Lambda \Gamma, r$ & ro & مكان التوم مفتوح على بعضه البعض منل & $1 \varepsilon$ \\
\hline . & . & r ז, ז & $\mathrm{v}$ & $\mathrm{V}, \mathrm{V}$ & ז & التهوية غير جيدة في مكان النوم & 10 \\
\hline . & . & $Y 7, \mathrm{~V}$ & $\Lambda$ & $V r, r$ & r & أل الاضاءة الموجودة غير مناسبة لنا & 17 \\
\hline - & - & or, r & 17 & $\sum \neg, \mathrm{V}$ & $1 \varepsilon$ & أشنعر بالضيق لأننا عددكبير ومساحة العنبر & iv \\
\hline$r, r$ & 1 & $\Lambda 7, \mathrm{~V}$ & ry & 1. & $r$ & نوعية الأكل داخل المؤسسة سيئة & 11 \\
\hline
\end{tabular}


إلى أن التكرارات والنسب المئوية لعبارات (الضغوط الاقتصادية) لمقياس الضغوط النفسية وأن إجابة معظم عينة الدراسة للعبارات اتجهت نحو الإجابنين (أحيانًا) بنسب تراوحت

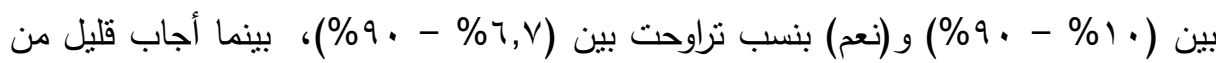

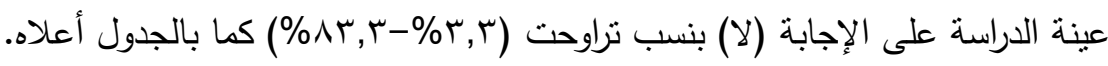

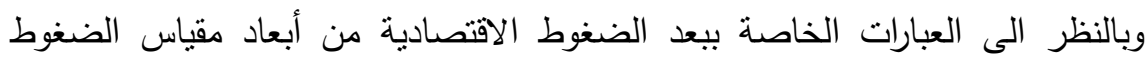

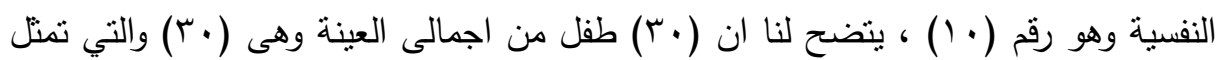
نسبة . . 1\% لا يتوفر لهم مكان مناسب للمذاكرة وهذا بدور يؤدى الى شعور هؤلاء الاطفال بالضيق لانهم لايملكون اماكن تساعدهم على تحصيل دورسهم المدرسية منل باقى زملاءهم فى المدرسة. كما نلاحظ من خلال الجدول أن نسبة (Y) طفل من اجمالى العينة (•r) وبنسبة

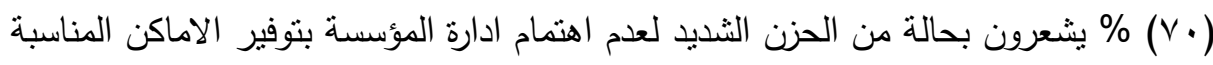
لهم للنوم وهذا يؤدى بدوره الى ضغوط نفسية لديهم.

كما نرى ان العبارات الخاصة بمصروفهم اليومى وكذللك اللبس و مكان النوم عند هؤلاء

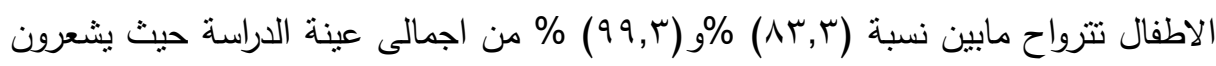
انهم محرمون من اقل الحقوق وعدم اهتمام المؤسسة بهم منل باقى زملاءهم فى المدرسة

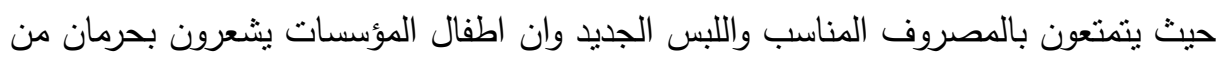
المصروف المناسب وكذلك من حرية اختيار اللبس. كما نلاحظ من خلال جدوال العبارات الخاص ببعد الضغوط الاقتصادية أن نسبة (ro)

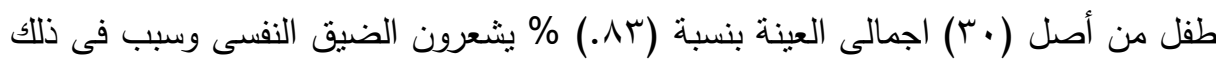
ان مكان نومهم فى عنبر مفتوح على بعضهم البعض مما يؤدى ذللك الى فقدان هؤلاء الاطفال

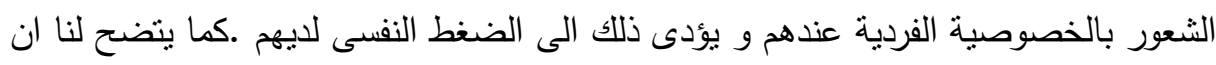

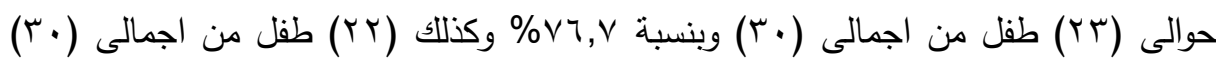

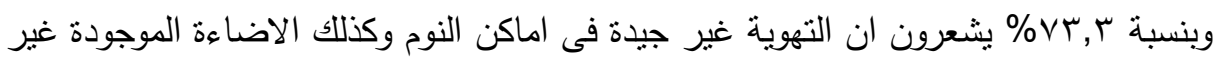
مناسبة. 
ويؤكد النموذج النفسى لريتشارد لازاروس مدى تأثير البيئة على الضغط النفسى عندهم

ويظهر ذللك فى البعد الاقتصادى عند الاطفال المراهقين مجهولى النسب حيث بعانوا نسبة لهردية كبير من الاطفال من مكان النوم والتهوية الغير جيدة وان حوالى TV\% بشعرون بضغط نفسى وضيق لأن عددهم كبير ومساحة العنبر صغيرة والتهوية غير جيدة، وهذا يؤدى بدوره الى ضغط نفسى عند هؤلاء الاطفال المراهقين مجهولى النسب فى المؤسسات الايوائية .

\section{تمنائي السراسلا}

- توجد علاقة ارتباطية ذات دالة معنوية عند مستوى معنوية (0.و •) بين الضغوط الاجتماعية والضغوط النفسية حيث بلغت قيم الدالة (1 (·ز •) وكان معامل الارتباط

$$
\cdot(\cdot 90 \leqslant)
$$

- توجد علاقة ارتباطية ذات دالة معنوية عند مستوى معنوية (0.و •) وبين الضغوط

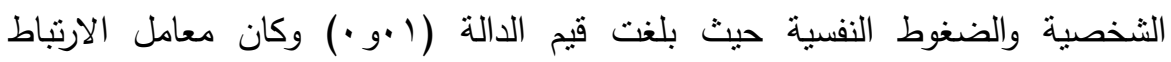

$$
\cdot(\cdot g \wedge r)
$$

- توجد علاقة ارتباطية ذات دالة معنوية عندى مستوى معنوية (0.و •) وبين الضغوط

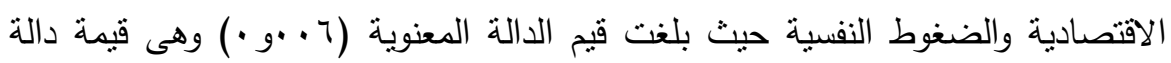

$$
\text { معنوياً عندى مستوى (0.و · ) وكانت قيمة معامل الأرتباط ( •9 گو · ). }
$$

\section{توكيايت التوراهة}

بناء على ماتوصلت اليه الدراسة من نتائج فقد نم التوصل الى مجموعة من التوصيات

$$
\text { وهى كالأتى: }
$$

ا. العمل على تذليل الصعوبات والمشكلات التى يعانى منها الأطفال مجهولى النسب فى

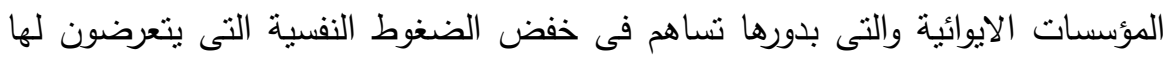


r. العمل على خلق وعى ثقافى لدى ادارة المؤسسات الايوائية بأهمية هذة المرحلة التى

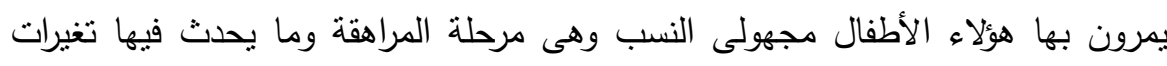
جسمية وصحية عندهم. r. يجب ان يكون هناك حصر للاحتباجات لهؤلاء الأطفال مجهولى النسب من قبل الادارة

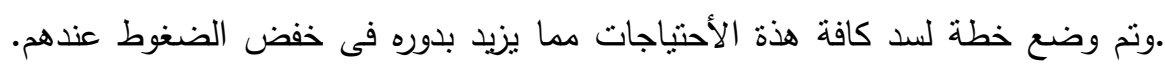
كما يساعدهم على اكتساب العديد من المهارات. ع. لابد من نوافر الامكانيات المادية التي تمكن القائمين على تربية هؤلاء الأطفال من أداء

$$
\text { دورهم على أكمل وجه. }
$$

ه. لابد من وجود قاعدة بيانات تفصيلية لهؤلاء الأطفال مجهولى النسب داخل المؤسسة والتى التى قد تساعد الاخصائيين الاجتماعيين على معرفة المشكلات التى يعانون منها وبالتالي

$$
\text { العمل على حلها. }
$$

\section{بحوث مفترحة ودراسات مستقبلية:}

1-أثز العبادات فى تخفيف الضغوط النفسية للأطفال مجهولى النسب فى المؤسسات

$$
\text { الايوائية. }
$$

r-دراسة العلاقة بين سمات الثخصية للأطفال مجهولى النسب وبين الضغوط النفسية. r-دراسة الصفحة النفسية للاطفال مجهولى النسب فى المؤسسات الايوائية.

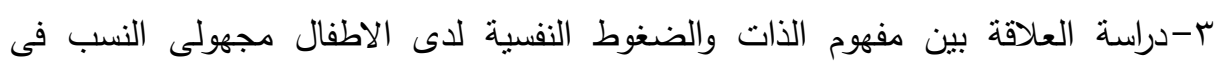
المؤسسات الايوائية.

\section{-2all}

أحمد إسماعيل( ( . ب): الفروق فى أساءة المعاملة وبعض متغيرات الثخصية بين الأطفال

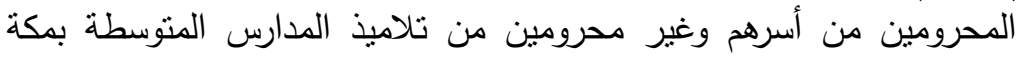

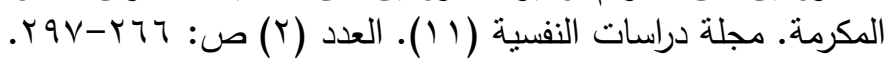




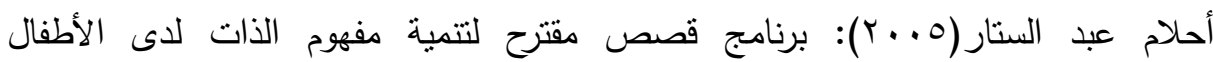

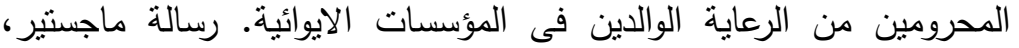
جامعة القاهرة، معهد الدراسات والبحوث التربوية.

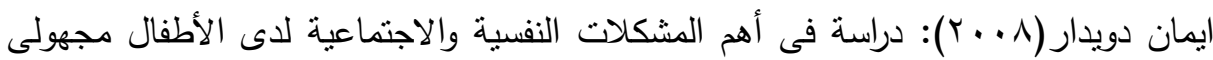

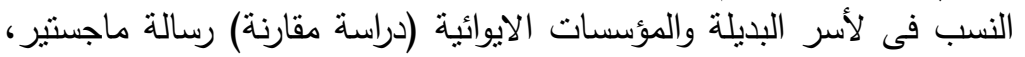

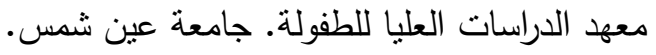

حمدى السكرى( . . † †): مصطلحات العلوم الاجتماعية، القاهرة، دار المعارف المصرية.

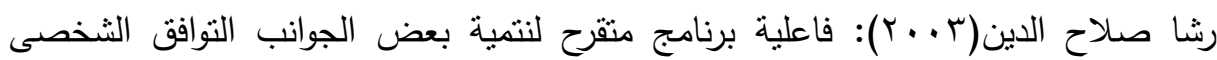

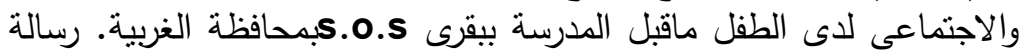
ماجسنتر • كلية تربية، جامعة طنطا.

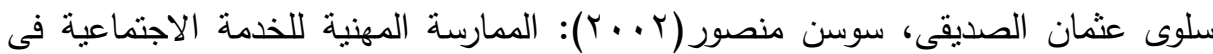
مجال المدرسة. القاهرة، دار المعرفية الجامعية.

عبداله بن ناصر (999 199): اطفال بل أسر ـ دار المعرفة الجامعية.

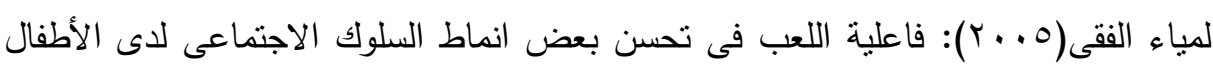

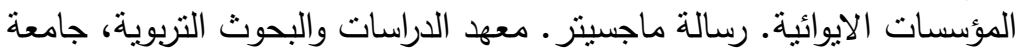

$$
\text { القاهرة. }
$$

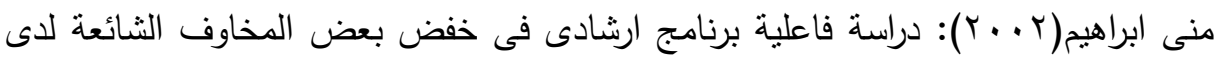

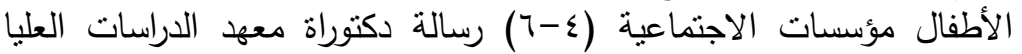

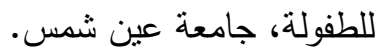

عبد الستار إبراهيم(• ( • ( ): السعادة الثخصية فى عالم مشحون بالتوتز وضغوط الحياة،

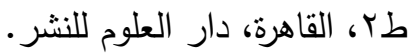

أحمد نايل الغرير، أحمد عبد اللطيف(9 . . ץ): التعامل مع الضغوط النفسية، عمان، دار

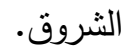

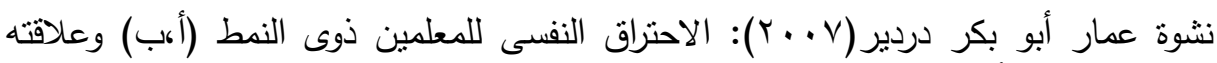
بأساليب مواجهة المشكلات، رسالة ماجستير ، كلية التربية، جامعة الفين الفيوم.

Aarnold, P. and Atkins, J. (2002): The social and emotional adjustment of hearing impaired children integrated in primary school, Education Research, Vol. 33, No.3, pp.223.

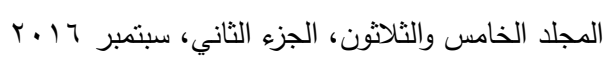




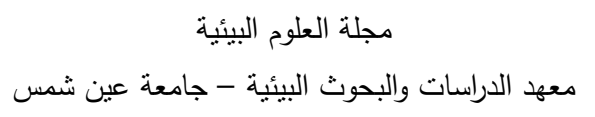

Adams, Economic (2000): Vocational Teacher stress and characteristics Journal of Vocational and technical Educational,Vol. 16, No.1, pp 7-22.

Charles, Linden (2002): What is stress and what is its connection to Anxiety? life wise publishing Ltd, New york.

Walker, C.M (2001): Psychological and biographical differences between secondary school teachers experiencing high and low levels of burnout, British Journal of Educational Psychology No.60, P.37.

Charles, E. schaefel, goward, I. millman (1981): how to heip childern weith common probems new york. pp.75-78

Benjamin L.T."psychology, Macmillan, New york,(1987) p.322 - 7 Cooper andMarshall :"Undertanding executive stress "New york , p.BL BOOK(1997), p119

Robert ,B:Adult developmente "New york :mac Millan publishing company,(1993). p.319

Bossier V .(1977) Intellectual emotional and social developmental deprived children .inderivtion and education edpringles MLK, $2^{\text {nd }}$, pp. 5-33. 
جمال أحمد شفيق وآخرون

\title{
STUDY PSYCHOLOGICAL STRESS AMONG ADOLESCENTS OF UNKNOWN PARENTAGE SHELTERED INSTITUTIONS
}

Shafik, G.A. ${ }^{(1)}$; Abdel Latif, R. ${ }^{(2)}$; Hany, A. F. ${ }^{(3)}$ and Ali, A. M.

1) Institute of Motherhood and Childhood, Ain Shams University 2) Faculty of Social Work, Helwan University 3) Institute of Environmental Studies and Research, Ain Shams University

\begin{abstract}
This current research drives at identifying the nature of resources of psychological stress, and finding out the relationship between economical, social, personal and psychological stress in those adolescents with unknown parents in residential facilities.

The research sample consists of (30) unknown parentage adolescents residents in Rescuing Childhood Institution, aged from (1417 yrs. olds). The study uses a primary data collection form designed by the researcher, Scale of Illegitimate Children Psychological Stress in Residential Facilities (by researchers), and an Open Questionnaire (by researchers).

Results indicate a positive correlation exists between economic stress and psychological stress among the unknown parentage adolescents in sheltering institutions. There is also a positive correlation between social stress and psychological stress and a positive correlation between personal and psychological stress among illegitimate adolescents lodged in residential facilities.
\end{abstract}

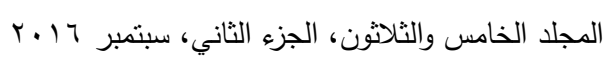

